\title{
INVESTIGATION OF ANTIVIRAL POTENTIAL OF LICORICE (GLYCYRRHIZA GLABRA L.) CRUDE EXTRACT AGAINST TOBACCO MOSAIC VIRUS
}

\author{
M. H. Ghodoum Parizipour ${ }^{1}$ and A. G. Shahriari ${ }^{2 *}$ \\ ${ }^{1}$ Department of Plant Protection, Agricultural Sciences and Natural Resources University of Khuzestan, Mollasani, Iran \\ ${ }^{2}$ Department of Agriculture and Natural Resources, Higher Education Center of Eghlid, Eghlid, Iran \\ "Corresponding author's email : Shahriari.ag@eghlid.ac.ir \\ Published online January 02, 2020
}

\begin{abstract}
Tobacco mosaic virus (TMV) is a devastating plant RNA virus infecting a wide range of plants causing considerable losses to agriculture products. Various dissemination means of TMV makes it particularly difficult to control. Application of plant-derived antiviral compounds has gained attention as one of the new control measures against viral diseases. This study was conducted to examine the antiviral effects of licorice (Glycyrrhiza glabra L.) crude extract (LCE) against TMV. To this end, TMV particles were purified and treated with different LCE concentrations $(0.5,1.0$, 2.5 and 5.0\%). Two hosts of TMV (Nicotiana glutinosa L. and N. tabacum L.) were mechanically inoculated with the LCE-treated TMV preparations and antiviral effects were assessed by measuring different disease parameters in the plants including infection rate, number of local lesion, symptom index, and virus accumulation. These parameters were significantly reduced when LCE was used to treat the TMV preparation or it was applied $24 \mathrm{~h}$ before TMV inoculation. An inverse relationship was found between LCE concentrations and various studied parameters. Application of LCE 24 $\mathrm{h}$ after TMV inoculation had no significant effect on disease parameters suggesting that LCE directly affects TMV rather than activating plant defence system. The results showed that licorice can be a promising source of novel antiviral compounds againts TMV.
\end{abstract}

Keywords: disease parameters, mechanical inoculation, local lesion, systemic infection.

\section{INTRODUCTION}

Licorice (Glycyrrhiza glabra L.) is a volunteer plant of the family Fabaceae originating from South Europe, North Africa and moderate regions of Asia. The root and rhizome of this plant have a brown/black colored cortex and yellow core which is frequently used as a herbal medicine (Morton, 1977). This plant grows in most provinces in Iran including Azarbaijan, Fars, Kermanshah, Kerman, Hamedan, Isfahan and Lorestan (Hajimahdipour et al., 2008). Licorice active compounds include glycyrrhizic acid, glabridin and liquiritin. Studies have shown that liquiritin, the main flavonoid found in licorice root, has antiviral effects (Kim et al., 2006; Ong and Lin, 2007). Glycyrrhizic acid has anti-inflammatory, wound-healing and antiviral effects (Ujisawa et al., 2000; $\mathrm{Fu}$ et al., 2005) and has been used to treat chronic hepatitis (Tanahashi et al., 2002). Licorice crude extract (LCE) has been shown to have antiviral effects against a wide range of human viruses such as varicella-zoster virus, cytomegalovirus, hepatitis $\mathrm{A}, \mathrm{B}$ and $\mathrm{C}$ viruses (HAV, $\mathrm{HBV}$ and $\mathrm{HCV}$, respectively), and human immunodeficiency virus (HIV) (Arase et al., 1997; Fiore et al., 2008; Mamedov and Egamberdieva, 2019; Ianevski et al., 2019).
In adition to humans and animals, plants are also affected by various types of viruses which may lead to different levels of loss according to virus type, host and environmental conditions. Tobacco mosaic virus (TMV) from the genus Tobamovirus and family Virgaviridae is one of the economically important and highly stable plant viruses with a positive single strand RNA genome encapsidated by a coat protein (King et al., 2012). The virus has a rigid rod-shaped particle of $18 \times 1300 \mathrm{~nm}$ size. TMV has a wide host range as it can infect more that 350 plant species from different families (King et al., 2012) including tobacco, tomato, pepper, eggplant, and bean, to name a few. In Iran, TMV has been reported from eggplant (Izadpanah, 1982; Alishiri et al., 2013), pepper (Manouchehri, 1968; Alishiri et al., 2013), tomato (Izadpanah, 1982; Alishiri et al., 2013), tobacco (Manouchehri, 1968; Alishiri et al., 2013) and potato (Alishiri et al., 2013) fields. The economic loss to crops infected by TMV is considerable as in some tomato fields up to $100 \%$ loss has been reported (Izadpanah, 1982). Symptoms caused by TMV include leaf mosaic, mottling, deformation, yellowing and size reduction, stunting, curling and total blight as well as fruit mosaic and deformation (Hull, 2014). In some experimental hosts of TMV such as Nicotiana glutinosa L., mechanically 
inoculated plants develop necrotic local lesions 24-48 hours post inoculation (hpi) (Jung et al., 2002). This has been used as an experimental index for pathogenecity assays of TMV (Hull, 2014).

The most common means of TMV dissemination is mechanical transmission through infected plant sap (Agrios, 2005). Moreover, the virus is easily transmitted by infested hands, tools, agricultural instruments and worker cloths. Insects such as aphids can not transmit TMV, while chewing pests, e.g. grasshoppers and caterpillars do transmit the virus. Cuttings and scions from infected plants, even without any visible symptoms, are able to transmit TMV (Agrios, 2005).

Application of chemical compounds as the first and the most effective method to control plant pests and diseases has been of interest to researchers and farmers for decades. Even after identification of hazardous environmental effects of such compounds and development of resistance among pests and pathogens, these chemicals are still used as the easiest and most accessible method to control pests and diseases (Kagale et al., 2004). Later, other methods for restricting pests and diseases in farms were developed which were more compatible with environment and agro-ecosystems, and were generally referred to as biocontrol. Diverse plant extracts have been accordingly examined to identify controlling or inhibitory compounds againts plant pathogens (Montanha et al., 2004; Othman and Shoman 2004; Bahraminejad et al., 2008; Bahraminejad et al., 2012; Awasthi et al., 2013; Ghasemi and Tabein, 2013; Rasoulpour et al., 2017). However, as mentioned above, the majority of studies have been concerned with human and animal pathogens. Given the economic importance of TMV and its increasing spread among different plants in Iran (Alishiri et al., 2013), developing new methods for reduction of the associated crop losses will be necessary. Considering the structural similarities between human and plant viruses in terms of genome type and coat proteins for instance, it is expected that LCE exhibits antiviral effects agatinst TMV. The aim of this work was to assess the antiviral potential of LCE against TMV infection in tobacco plants. Furthermore, different concentrations and application times of LCE were evaluated for their antiviral effects in TMV-inoculated plants.

\section{MATERIALS AND METHODS}

Plant material: Two plant species, $N$. tabacum var. Turkish and N. glutinosa, were used as systemic and local lesion hosts of TMV, respectively. Seeds of these plants were sown in pots containing cocopeat and perlite $(1: 1)$ and irrigated daily. The emerged seedlings were transferred into new pots containing peat moss and soil
(1:2) and kept at greenhouse conditions: $25^{\circ} \mathrm{C}, 16: 8 \mathrm{~h}$ photoperiod, and $40 \%$ relative humidity.

Virus propagation: In order to propagate TMV, Nicotiana tabacum var. Turkish plantlets were mechanically inoculated at four-leaf stage. The inoculum was prepared from a TMV-infected $N$. tabacum var. Turkish. The symptomatic apical leaves of the infection source were harvested and homogenized in a mortar while adding approximately 1-2 fold weight of $0.01 \mathrm{M}$ potassium phosphate buffer ( $\mathrm{pH}$ 7). Plant sap was then rubbed on carborundum-dusted leaves of healthy tobacco seedlings. After 2-3 weeks and when symptoms were observed, the plants were re-inoculated to obtain more infected tissue. Symptomatic leaves were harvested from TMV-inoculated plants and stored at $-20^{\circ} \mathrm{C}$ for further experiments.

Virus purification: TMV was purified according to the method described by Bateman and Chant (1979) with some modifications. Approximately $40 \mathrm{~g}$ of infected tissue was homogenized in $200 \mathrm{ml}$ of $0.1 \mathrm{M}$ potassium phosphate buffer ( $\mathrm{pH} \quad 7$ ) containing $0.01 \%$ sodium metabisulphide. The extract was clarified by passing through four layers of cheese cloth. Approximately $20 \mathrm{ml}$ of n-butanol was added to $200 \mathrm{ml}$ of the clarified extract while vigorously stirring, and then shaked for $45 \mathrm{~min}$. The mixture was centrifuged at $9500 \mathrm{rpm}$ (rotor type SS34 ) for $30 \mathrm{~min}$ and the pellet was discarded. Then eight grams of polyethylene glycol (PEG) 6000 was gradually added while stirring at $4^{\circ} \mathrm{C}$. After PEG was dissolved completely, the mixture was centrifuged as above. This time, the supernatant was discarded and the pellet was resuspended in $43 \mathrm{ml}$ of $0.05 \mathrm{M}$ potassium phosphate buffer $(\mathrm{pH} 7)$ and incubated at $4{ }^{\circ} \mathrm{C}$ for one hour. Then the mixture was centrifuged for $15 \mathrm{~min}$ at $10000 \mathrm{~g}$. Virus particles were isolated by adding $1.5 \mathrm{~g}$ of $\mathrm{NaCl}$ and PEG (1:1) and centrifuging at $10000 \mathrm{~g}$ for $15 \mathrm{~min}$. The pellet was dissolved in $4.3 \mathrm{ml}$ of $0.05 \mathrm{M}$ potassium phosphate buffer $(\mathrm{pH} \mathrm{7)}$ and then centrifuged at $10000 \mathrm{~g}$ for five minutes. Finally, the supernatant containing partially purified TMV was stored at $-20^{\circ} \mathrm{C}$. The quality and quantity of the virus preparation was assessed using NANODROP spectrophotometer (Thermo Scientific, USA).

Preparation of licorice crude extract (LCE): Fresh tissue of licorice root was washed and completely dried. An extraction method using methanol was applied according to Sabouri Ghanad et al. (2013). Briefly, one gram of ground root tissue was mixed with $70 \mathrm{ml}$ of absolute methanol and shaked for $24 \mathrm{~h}$ at room temperature. The resulting extract was passed through $0.45 \mu \mathrm{m}$ filter and dried using a Vacufuge concentrator (Eppendorf, Germany) for compete removal of methanol. The pellet was then resuspended in deionized distilled water $\left(\mathrm{ddH}_{2} \mathrm{O}\right)$ and diluted to prepare different 
concentrations of LCE including 0.5, 1.0, 2.5 and 5\% $(\mathrm{v} / \mathrm{v})$, and stored at $4^{\circ} \mathrm{C}$ for further tests.

Antiviral effect assay: In order to investigate the antiviral effects of LCE, TMV preparation was treated with different LCE concentrations including 0 (control), $0.5,1.0,2.5$ and 5.0 percent, and then used to inoculate plants machanically as described above. An equal volume of $\mathrm{ddH}_{2} \mathrm{O}$ was used instead of LCE to form the control treatment. In order to test the antiviral effect of LCE on defence response of the plants against TMV, two sets of treatments (the aforementioned concentrations of LCE 24 $\mathrm{h}$ before or $24 \mathrm{~h}$ after mechanical inoculation of tobacco plants by untreated TMV inoculum) were applied. The infection rate and the number of local lesion were calculated and statistically analyzed as described by Rasoulpour et al. (2017). In case of local lesion host, the number of lesions developed 24-48 hpi was considered as an index for antiviral assay. To reduce experimental error, leaves of a similar size were selected for inoculation. Systemic infection was assesed using Indirect-ELISA (see below) 15 days post inoculation (dpi). After the emergence of symptoms in the systemic host, the plants were visually scored from one to four [one, mild mosaic; two, moderate mosaic; three, moderate mosaic and malformation; four, severe mosaic and malformation], and the symptom index was recorded for each treatment. The experimental treatments in this study included (1) different concentrations of LCE and (2) the time of treatment. Ten plants were used per treatment and the experiment was repeated twice.

Indirect enzyme-linked immunosorbent assay (Indirect-ELISA): Indirect-ELISA with polyclonal antibody against TMV coat protein (BIOREBA, Switzerland) was performed to detect TMV in inoculated plants using the method described by Clark and Adams (1977). Approximately $100 \mu \mathrm{l}$ of the diluted antibody was added to each well of a polystyrene microtiter plate, except blank. Blank well was filled with $100 \mu \mathrm{l}$ of substrate buffer $(9.7 \%$ diethanolamide, $0.2 \mathrm{M}$ sodium azide $\left[\mathrm{NaN}_{3}\right], \mathrm{pH} 9.8$ ). The plate was covered with a lid and incubated at $37^{\circ} \mathrm{C}$ for four hours in a moist chamber and then the plate was washed three times with washing bufer (PBS, $0.5 \%$ Tween-20) and dried well. Plant tissues $(\sim 500 \mathrm{mg})$ was homogenized in a 10 -fold volume of extraction buffer (PBS, 0.5\% Tween-20, 2\% PVP), and the wells (except blank) were filled with $100 \mu \mathrm{l}$ of homogenate. Control wells (buffer, healthy plant extract as negative and TMV-infected plant extract as positive controls; two per control) were included. The plate was covered and incubated at $4^{\circ} \mathrm{C}$ overnight. Washing step was repeated as above. IgG-alkaline phosphatase (conjugate) was diluted to a ratio of 1:5000 in PBSTween-20 buffer and $100 \mu$ lof the diluted conjugate was added to each well except blank. The plate was covered and incubated at $37^{\circ} \mathrm{C}$ for four hours in a moist chamber and then washed as above. The substrate $p$-nitrophenyl phosphate $(1 \mathrm{mg} / \mathrm{ml})$ was dissolved in the substrate buffer and $200 \mu \mathrm{l}$ of the resulting solution was added per well. The plate was incubated in dark chamber at room temperature. ELISA plate was analyzed using Thermo Labsystems microplate reader (Thermo Scientific, Germany) and the optical density (OD) was measured at wave length of $405 \mathrm{~nm}$. Samples with an OD greater than $M+3 S D$ ( $M=$ mean OD value of negative controls, $S D=$ mean standard deviation value of negative controls) were considered positive.

Statistical analysis: A nonparametric statistical approach was applied to analyze the data collected from infection rates and symptom index assays since they did not show a normal distribution in primary analysis (Richardson, 2015). Infection rates were first calculated, in percentages, dividing the number of infected plants by the total number of inoculated plants and then transformed to arcsine square root values for analysis of variance (ANOVA) using SPSS software (ver. 24.2). Duncan's multiple range test was used to determine any significant difference at $P \leq 0.01$ and $P \leq 0.05$ levels among the treatments. In case of local lesion and OD data, however, parametric statistics were used to analyze the data. Mean \pm SE values were calculated for the treatments and compared as above.

\section{RESULTS}

Effect of LCE on systemic infection: Systemic leaf mosaic and deformation was observed on N. tabacum var. Turkish 15 dpi (Figure 1A). Infection rates were calculated for TMV-inoculated plants treated with various concentrations of LCE at different times (Figure 1B). Indirect-ELISA results showed that TMV preparations treated with different concentratons of LCE had significantly lower infection rates compared to untreated viral preparations $(P \leq 0.05)$. Application of LCE $24 \mathrm{~h}$ before TMV inoculation similarly reduced infection rates compared to control $(P \leq 0.05)$, whereas its application $24 \mathrm{~h}$ after TMV inoculation had no significant effect on the infection rate (Figure 1B).

Effect of LCE on local lesion development: Severe reaction of necrotic local lesions and chlorosis were displayed on the leaves of tobacco plants machanically inoculated with TMV 48 hpi (Figure 2A). Statistical analysis showed that treatment of TMV preparation with LCE significantly $(P \leq 0.05)$ reduce the number of local lesions on tobacco leaves compared to control (Figure 2B). Moreover, no chlorosis was observed on the leaf of plants inoculated with LCE-treated TMV preparation (Figure 2A). Application of LCE $24 \mathrm{~h}$ before TMV inoculation similarly reduced the number of local lesions compared to control $(P \leq 0.05)$ while its application $24 \mathrm{~h}$ 
after TMV inoculation had no significant effect on the number of local lesions (Figure 2B).

Effect of LCE on symptom index and virus accumulation: Plants inoculated with LCE-treated TMV displayed significantly $(P \leq 0.05)$ lower symptom indices compared to other treatments (Figure 3A). Treatment of tobacco plants with LCE $24 \mathrm{~h}$ before or $24 \mathrm{~h}$ after TMV inoculation had no significant effect on symptom development (Figure 3A). Figure 3B shows ELISA extinction (OD) values which were considered as an index of TMV accumulation within the plant host (Kuhn et al., 1986; Dziewońska and Waś, 1994; Ogbe et al., 2003). Data analysis showed that treatment of TMV with different concentrations of LCE significantly reduced ELISA extinction in inoculated plants. Similarly, application of LCE $24 \mathrm{~h}$ before TMV inoculation significantly reduced the number of local lesions compared to control $(P \leq 0.05)$. There was no significant difference among the other treatment, that is, application of LCE $24 \mathrm{~h}$ after TMV inoculation (Figure 3B). Moreover, a positive correlation was observed between symptom index and TMV accumulation in tobacco plants.

Effect of LCE concentration and application time on anti-TMV activity: Statistical analysis showed that LCE concentration significantly $(P \leq 0.05)$ affected the average values of disease parameters in TMV-infected plants (Figures 1-3). Generally, concentration of LCE used to treat TMV preparation was negatively correlated with the average values of disease parameters in tobacco plants as increased LCE concentration was associated with ameliorated disease parameters. In case of all disease parameters, a significant difference was observed between 0.5 and $5.0 \%$ concentrations of LCE ( Figures 13). Except for local lesions, increasing LCE concentration up to $1.0 \%$ did not significantly affect any of the disease parameters at any application time. When LCE concentration was increased to $2.5 \%$, disease parameters were significantly reduced compared to control (Figures 1-3). However, no significant difference was found between application times of LCE.
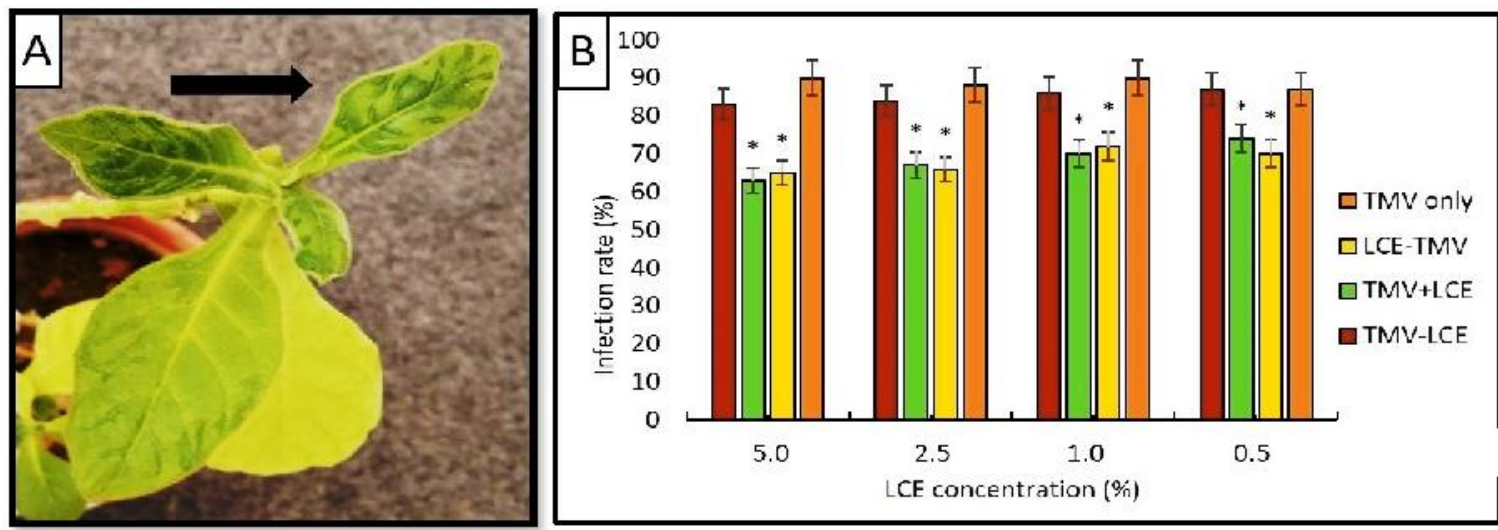

Figure 1. Leaf mosaic and deformation observed on TMV-inoculated tobacco (Nicotiana tabacum var. Turkish) plants 15 days post inoculation (A) and average TMV infection rates under experimental treatments including different concentrations of licorice crude extract (LCE) and their application times ( $24 \mathrm{~h}$ before [LCE-TMV], concurrent with [TMV+LCE] and $24 \mathrm{~h}$ after [TMV-LCE] inoculation) compared to control (TMV only) treatment (B). * Significant value at $\mathrm{p}=0.05$.

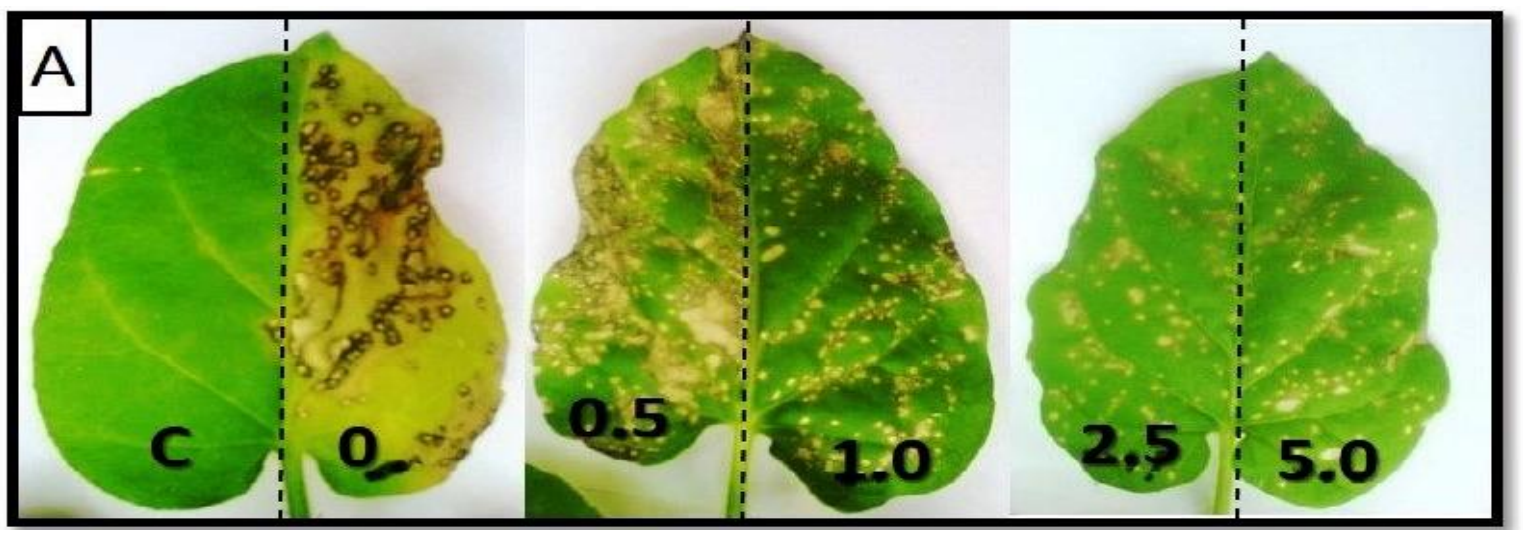




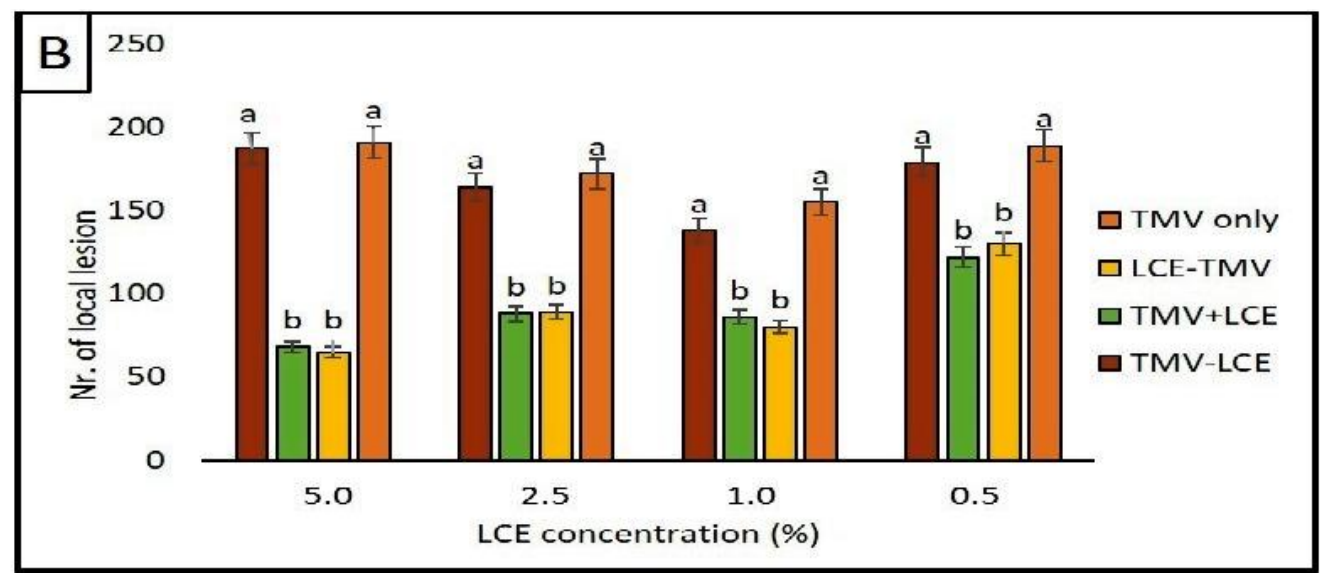

Figure 2. Local lesions developed on TMV-inoculated tobacco (Nicotiana glutinosa) plants 48 hours post inoculation (A) and average number of local lesions caused by TMV inoculation under experimental treatments including different concentrations of licorice crude extract (LCE) and their application times (24 h before [LCE-TMV], concurrent with [TMV+LCE] and $24 \mathrm{~h}$ after [TMV-LCE], inoculation) compared to control (TMV only) treatment (B). Letters on bars show significant differences between treatments according to the results of Duncan's multiple range test.
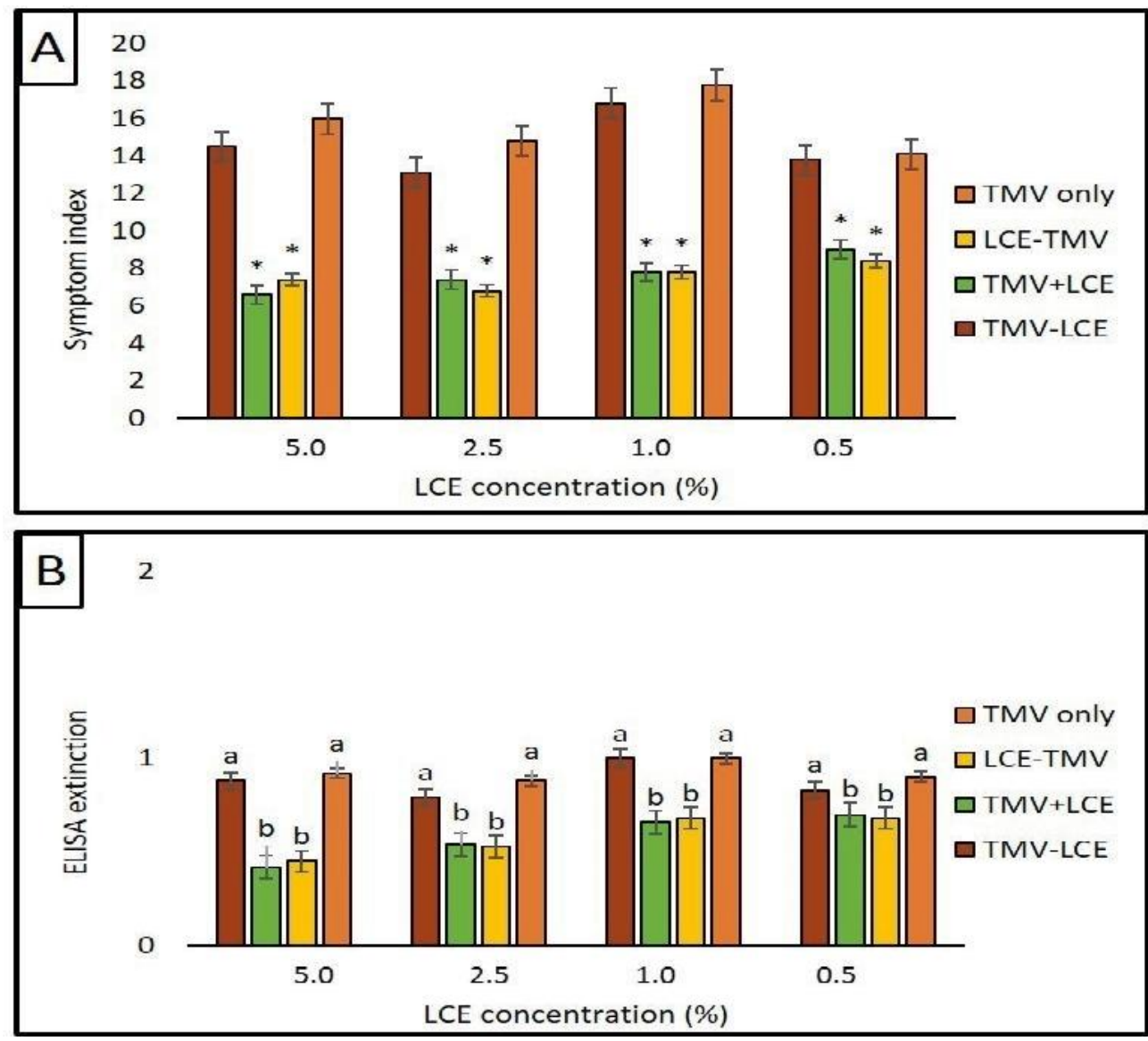

Figure 3. Symptom index (A) and ELISA extinction (B) values determined for TMV-inoculated tobacco (Nicotiana tabacum var. Turkish) plants 15 days post inoculation under experimental treatments including different concentrations of licorice crude extract (LCE) and their application times ( $24 \mathrm{~h}$ before [LCE-TMV], concurrent with [TMV+LCE] and $24 \mathrm{~h}$ after [TMV-LCE], inoculation) compared to control (TMV only) treatment (B). * Significant at $\mathbf{p}=\mathbf{0 . 0 5}$. Letters on bars show significant differences between treatments according to the results of Duncan's multiple range test. 


\section{DISCUSSION}

Antiviral effects of plant extracts and plantderived compounds against a number of plant viruses have been reported (Iftikhar et al., 2013; Milad et al., 2014; Rasoulpour et al., 2017). Here, we first demonstrated the antiviral effects of LCE against TMV. Similar to the previous studies emphasizing the investigation of antiviral effects in both systemic and local lesion hosts (e.g. Rasoulpour et al., 2017), antiviral effects were assesed using two antiviral indices including infection rate and number of local lesions in N. tabacum var. Turkish and N. glutinosa, respectively, both of which showed a significant reduction when LCE-treated TMV preparations were used to inoculate tobacco plants. Although mechanical inoculation was shown to be the most effective mean of TMV transmission in greenhouse studies (Takebe and Otsuki 1969; Dawson et al., 1975), we could not obtained a $100 \%$ infection even using untreated TMV preparation (Figure 1). Similarly, this phenomenon has been reported in other studies (Rasoulpour et al., 2017). This might be due to the fact that many environmental factors influence virus infections resulting in variations among infection rates (Hull, 2014). To better investigate the antiviral effects of LCE, we determined two more plant disease parameters including symptom index and virus accumulation of TMV in N. tabacum var. Turkish plants both of which confirmed the antiviral effects of LCE (Figure 3). The symptom index was positively correlated with TMV accumulation in tobacco plants (Figure 3 ) which has been similarly found in other plant-virus interactions (Suzuki et al., 1995; Ogbe et al., 2003; Díaz-Pendón et al., 2005). There was a correlation between LCE concentration used to treat TMV preparation and its antiviral effect (Figures 1-3), and increased concentration was associated with lower severity of disease parameters in TMV-challenged tobacco plants (Figures 1-3). In vitro studies have shown that replication of human viruses such as HIV (Ito et al., 1988) and HAV (Crance et al., 1994) is reduced by LCE. These two human viruses have a genome type similar to that of TMV i.e. ssRNA (King et al., 2012). Therefore the observed reduction of disease parameters in TMVinoculated tobacco plants might be due to inhibition of the viral replication within plant cells. Stability of antiviral agents under different conditions is an important characteristic which needs to be recovered for any antiviral substance (Rasoulpour et al., 2017). Our results showed that LCE is still active $24 \mathrm{~h}$ post application on tobacco leaves and can negatively affect disease parameters in TMV-inoculated plants (Figures 1-3). Application of LCE $24 \mathrm{~h}$ after TMV inoculation did not result in any significant effect on the disease parametars (Figure 1-3). A similar observation was reported in case of other antiviral plant extracts from sage (Salvia officinalis L.), marigold (Tagetes erecta L.), four o'clock flower (Mirabilis jalapa L.) and prickly pear [Opuntia ficus-indica (L.) Miller] examined against TMV (Ghasemi and Tabein, 2013; Rasoulpour et al., 2017). This suggests that LCE directly affect TMV infection rather than activating the plant defence system as TMV enters parenchymal cells within less than 12 hpi (Kawakami et al., 2004), avoiding exposure to LCE. The direct effect of LCE-derived antiviral compounds against human viruses (Ito et al., 1987; Crance et al., 1994) reinforces the hypothesis based on which LCE affects TMV infection directly. Although LCE has been frequently used as an antiviral agent in numerous studies (Kim et al., 2006; Ong and Lin, 2007), this is the first report of its application against a plant virus. According to the results, it can be concluded that licorice is a promising source for identification, isolation and purification of antiviral compounds such as polysaccharides (Silva et al., 2011), lipids (Bezic et al., 2013) and proteins (Rasoulpour et al., 2017). Further experiments are required to identify the inhibitory mechanism of LCE againts TMV infection.

Conclusion: It has been shown that llicorice extract is able to inhibit human viruses. However, its antiviral effect against plant viruses has not been studied yet. Here we evaluated the potential of licorice crude extract for inhibition of a plant virus (TMV) in tobacco hosts. The results of this study shows that licorice is a promising natural source for identification of novel antiviral copounds against plant veruses leading reduced use of chemicals in cultivated fields.

Acknowledgments: This work was supported by funds [Grant Number: 961.18] from Department of Plant Protection, Agricultural Sciences and Natural Resources University of Khuzestan, Mollasani, Iran.

\section{REFERENCES}

Agrios, J.N. (2005). Plant Pathology. 5th Ed. Elsevier Academic Press USA; New York. 952 p.

Alishiri, A., F. Rakhshandehroo, H.R. Zamanizadeh, and P. Palukaitis (2013). Prevalence of Tobacco mosaic virus in Iran and evolutionary analyses of the coat protein gene. Plant Pathol. 29(3): 260-273.

Arase, Y., K. Ikeda, N. Murashima, K. Chayama, A. Tsubota, I. Koida, Y. Suzuki, S. Saitoh, M. Kobayashi, and H. Kumada (1997). The long term efficacy of glycyrrhizin in chronic hepatitis C patients. Cancer 79: 1494-1500.

Awasthi, L.P., S.P. Singh, H.N. Verma, and S. Kluge (2013). Further studies on the antiviral agent isolated from host plants, pre-treated with Boerhaavia diffusa glycoprotein. Virol. Mycol. 3: 1-9. 
Bahraminejad, S., R.E. Asenntorfer, I.T. Riley, and C.J. Schultz (2008). Analysis of the antimicrobial activity of flavonoids and saponins isolated from the shoots of oats (Avena sativa L.). J. Phytopathol. 156: 1-7.

Bahraminejad, S., S. Abbasi, S.M. Maassoumi, and S. Tabein (2012). Evaluation of inhibitory effects of extracts of plants from western Iran against Phytophthora drechsleri. Aust. J. Crop Sci. 6: 255-260.

Bateman, J.G. and S.R. Chant (1979). A modification of the polyethylene glycol technique for the purification of small quantities of tobacco mosaic virus. Microbios 25: 33-43.

Bezic, N., V. Dunkic, and E. Vuko (2013). Antiphytoniral activity of essential oils of some Lamiaceae species and there most important compounds on CMV and TMV. In A. MendezVilas (Ed.), Microbial pathogens and strategies for combating them. Science, Technology and Education Formatex Research Center; Badajoz (Spain). pp. 982-988.

Clark, M.F. and A.N. Adams (1977). Characteristics of the microplate method of enzyme-linked immunosorbent assay for the detection of plant viruses. J. Gen. Virol. 34: 475-483.

Crance, J.M., F. Leveque, E. Biziagos, H. VanCuyckGandre, A. Jouan, and R. Deloince (1994). Studies on mechanism of action of glycyrrhizin against hepatitis A virus replication in vitro. Antiviral Res. 23: 63-76.

Dawson, W.O., D.E. Schlegel, and M.C.Y. Lung (1975). Synthesis of tobacco mosaic virus in intact tobacco leaves systemically inoculated by differential temperature treatment. Virol. 65(2): 565-573.

Díaz-Pendón, J.A., R. Fernández-Muñoz, M.L. GómezGuillamón, and E. Moriones (2005). Inheritance of resistance to Watermelon mosaic virus in Cucumis melo that impairs virus accumulation, symptom expression, and aphid transmission. Phytopathol. 95(7): 840-846.

Dziewońska, M.A. and M. Waś (1994). Diploid genotype DW. 84-1457, highly resistant to potato leafroll virus (PLRV). Potato Res. 37(3): 217-224.

Fiore, C., M. Eisenhut, R. Krausse, E. Ragazzi, D. Pellati, D. Armanini, and J. Bielenberg (2008). Antiviral effects of Glycyrrhiza species. Phytother. Res. 22(2): 141-148.

Fu, B., J. Liu, H. Li, L. Li, F.S. Lee, and X. Wang (2005). The application of macroporous resins in the separation of licorice flavonoids and glycyrrhizic acid. J. Chromatogr. A. 1089: 1824.
Ghasemi, S. and S. Tabein (2013). Evaluation of antiviral effects of plant extracts against Tobacco mosaic virus. Plant Prot. J. 6(4): 353-363.

Hajimahdipour, H., Y. Amnzadeh, T. Hasanlou, M. Shekarchi, Z. Abedi, and M. Pirali Hamedani (2008). Investigation of the quality of licorice root collected from its different habitants in Iran. J. Med. Plants 7(3): 106-114.

Hull, R. (2014). Matthews' plant virology. 5th Ed. Academic Press USA; New York. 1118 p.

Ianevski, A., P.I. Andersen, A. Merits, M. Bjørås, and D. Kainov (2019). Expanding the activity spectrum of antiviral agents. Drug Discov. Today 24(5):1224-1228.

Iftikhar, S., A.A. Shahid, S.H. Javed, I.A. Nasir, B. Tabassum, and M. Saleem Haider (2013). Essential oils and latices as novel antiviral agent against Potato leaf roll virus and analysis of their phytochemical constituents responsible for antiviral activity. J. Agric Sci. 5: 167-188.

Ito, M., A. Sato, K. Hirabayashi, F. Tanabe, S. Shigeta, M. Baba, E. De Clercq, H. Nakashima, and N. Yamamoto (1988). Mechanism of inhibitory effect of glycyrrhizin on replication of human immunodeficiency virus (HIV). Antiviral Res. 10(6): 289-98.

Ito, M., H. Nakashima, M. Baba, R. Pauwels, E. De Clercq, S. Shigeta, and N. Yamamoto (1987). Inhibitory effect of glycyrrhizin on the in vitro infectivity and cytopathic activity of the human immunodeficiency virus [HIV (HTLVIII/LAV)]. Antiviral Res. 7: 127-137.

Izadpanah, K. (1982). Comprehensive list of virus and virus-like diseases in Fars Province, Shiraz Agriculture Jihad, Govt. Iran., Shiraz.

Jung, H.W., W.S. Yun, Y.I. Hahm, and K.H. Kim (2002). Characterization of Tobacco mosaic virus isolated from potato showing yellow leaf mosaic and stunting symptoms in Korea. Plant Dis. 86(2): 112-117.

Kagale, S., T. Marimuthu, B. Thayumanavan, R. Nandakumar, and R. Samiyappan (2004). Antimicrobial activity and Induction of systemic resistance in rice by leaf extract of Datura metel against Rhizoctonia solani and Xanthomonas oryzae pv. oryzae. Physiol. Mol. Plant Pathol. 65: 91-100.

Kawakami, S., Y. Watanabe, and R.N. Beachy (2004). Tobacco mosaic virus infection spreads cell to cell as intact replication complexes. Proc. Natl. Acad. Sci. U.S.A. 101(16): 6291-6296.

Kim, Y.W., S.H. Ki, J.R. Lee, S.J. Lee, C.W. Kim, S.C. Kim, and S.G. Kim (2006). Liquiritigenin, an agly-cone of liquiritin in Glycyrrhizae radix, prevents acute liver injuries in rats induced by 
acetaminophen with or without buthionine sulfoximine. Chem. Biol. Interact. 161: 125-138.

King, A.M.Q., M.J. Adams, E.B. Carstens, and E.J. Lefkowitz (2012). Virus taxonomy: Classification and nomenclature of viruses Ninth report of the International Committee on Taxonomy of Viruses. Elsevier Academic Press USA; New York. 1327 p.

Kuhn, C.W., C.P. Benner, and H.A. Hobbs (1986). Resistance responses in cowpea to southern bean mosaic virus based on virus accumulation and symptomatology. Phytopathol. 76(8): 795-799.

Mamedov, N.A. and D. Egamberdieva (2019). Phytochemical constituents and pharmacological effects of licorice: a review. In M. Ozturk and K.R. Hakeem (Eds.), Plant and human health, 3. Springer; Cham (Switzerland). pp. 1-21.

Manouchehri, A. (1968). Plant Viral Diseases. Tehran University Press; Tehran (Iran).

Milad, R., S. El-Ahmady, and A.N. Singab (2014). Genus Kalanchoe (Crassulaceae): A review of its ethnomedicinal, botanical, chemical and pharmacological properties. Eur. J. Med. Plants 4(1): 86-104.

Montanha, J.A., P. Moellerke, S.A.L. Bordignon, E.P. Schenkel, and P.M. Roehe (2004). Antiviral activity of Brazilian plant extracts. Acta Farmaceutica Bonaerense 23: 183-186.

Morton, J.F. (1977). Major medicinal plants: Botany, culture, and uses. 1st Ed. Thomas; Springfield (USA). $429 \mathrm{p}$.

Ogbe, F.O., G.I. Atiri, A.G. Dixon, and G. Thottappilly (2003). Symptom severity of cassava mosaic disease in relation to concentration of African cassava mosaic virus in different cassava genotypes. Plant Pathol. 52(1): 84-91.

Ong, J. and B. Lin (2007). Separation of liquiritin by stimulated moving bed chromatography. J. Chromatogr. A. 1145: 190-194.

Othman, B.A. and S.A. Shoman (2004). Antiphytoviral activity of the Plectranthus tenuiflorus on some important viruses. Int. J. Agriculture Biol. 6: 844-849.

Rasoulpour, R., A. Afsharifar, K. Izadpanah, and M. Aminlari (2017). Purification and characterization of an antiviral protein from prickly pear (Opuntia ficus-indica (L.) Miller) cladode. Crop Prot. 93: 33-42.

Richardson, A.M. (2015). Nonparametric statistics: a step-by-step approach. Int. Stat. Rev. 83(1): 163 164.

Sabouri Ghanad, M., A. Mohamadi, S. Safialahi, and J. Fardmal (2013). The evaluation of methanolic extract of glycyrrhiza glabra effect on the replication of herpes simplex virus type 1 in vero cell line. Sci. J. Hamadan Univ. Med. Sci. 20(4): 325-332.

Silva, A.R.A., S.M. Morais, M.M.M. Marques, D.M. Lima, S.C.C. Santos, R.R. Almeida, I.G.P. Vieira, and M.I.F. Guedes (2011). Antiviral activities of extracts and phenolic components of two Spondias species against dengue virus. J. Venomous Anim. Toxins 17: 406-413.

Suzuki, M., S. Kuwata, C. Masuta, and Y. Takanami (1995). Point mutations in the coat protein of cucumber mosaic virus affect symptom expression and virion accumulation in tobacco. J. Gen. Virol. 76(7): 1791-1799.

Takebe, I. and Y. Otsuki (1969). Infection of tobacco mesophyll protoplasts by tobacco mosaic virus. Proc. Natl. Acad. Sci. U.S.A. 64(3): 843-848.

Tanahashi, T., T. Mune, H. Morita, H. Tanahashi, Y. Isomura, T. Suwa, H. Daido, C.E. GomezSanchez, and K. Yasuda (2002). Glycyrrhizic acid suppresses type 2 11ß-hydroxysteroid dehydrogenase expressions in vivo. J. Steroid Biochem. Mol. Biol. 80: 441-447.

Ujisawa, Y., M. Sakamoto, M. Matsushita, T. Fujita, and K. Nishioka (2000). Glycyrrhizin inhibits the lytic pathway of complement: Possible mechanism of its anti-inflammatory effect on liver. Microbiol. Immunol. 44: 799-804. 